\title{
Respiratory infection and otitis media visits in relation to pneumococcal conjugate vaccine use in Saskatchewan
}

\author{
Ngoc-Hang Khuc MSc${ }^{1}$, Ben Tan $\mathrm{MD}^{2}$, Rosalie Tuchscherer RN ${ }^{3}$, Nigel SB Rawson PhD" , Philippe De Wals MD PhD 1,5,6
}

\begin{abstract}
N-H Khuc, B Tan, R Tuchscherer, NSB Rawson, P De Wals. Respiratory infection and otitis media visits in relation to pneumococcal conjugate vaccine use in Saskatchewan. Can J Infect Dis Med Microbiol 2013;24(4):179-184.
\end{abstract}

BACKGROUND: In Saskatchewan, pneumococcal conjugate vaccination (PCV) was offered to high-risk children in 2002 and to all infants in 2005.

OBJECTIVE: To describe trends in the frequency of medical visits for lower respiratory tract infection (LRI) and otitis media (OM) in relation to PCV use during the period 1990 to 2008.

METHODS: Statistics regarding the number of children covered by the health insurance plan, PCV administration, and medical visits with a diagnostic code associated with LRI and OM were provided by Saskatchewan Health. Monthly rates were analyzed using dynamic state space models.

RESULTS: In all series, there was a marked seasonal cycle and some higherthan-expected winter peak values, possibly associated with epidemics of specific respiratory viruses. Three abrupt decreases in baseline rate were observed for LRI and the final one, in February 2007, could be related to the increased proportion of children vaccinated with PCV. There was no statistical correlation between PCV use and OM visit frequency.

CONCLUSION: Many environmental, biological and administrative factors may influence health services use, and an effect of low magnitude of a particular vaccine pertaining to nonspecific outcomes could be obscured in time-series analyses.

Key Words: Otitis media; Pneumococcal conjugate vaccine; Pneumonia; Program evaluation

The seven-valent pneumococcal conjugate vaccine (PCV-7) was licensed in Canada in June 2001, and a three-dose infant primary series with a toddler booster dose was recommended (1). In Saskatchewan, PCV-7 was first offered to high-risk children $<2$ years of age in September 2002. The publicly funded program was expanded to cover all high-risk children $<5$ years of age in October 2003. Two years later, PCV-7 was introduced for the routine immunization of all infants born on or after April 1, 2005, and no catch-up was recommended for older children. The 13-valent vaccine (PCV-13) replaced PCV-7 in July 2010. A 2+1 PCV-13 schedule was recommended for low-risk infants in April 2012.

PCV-7 was primarily designed to prevent invasive pneumococcal infections. As shown in randomized trials, this vaccine has the potential to prevent all-cause pneumonia and otitis media $(O M)(2-4)$. The impact of vaccine use at the population level should be carefully evaluated because herd protection and serotype replacement may, respectively, enhance or erode benefits (5-7). In Canada, the overall impact of PCV-7 use has been extensively assessed in Quebec, where a 2+1 schedule is recommended for low-risk children (8-10). Also, in Alberta, the effectiveness of a $3+1$ schedule against invasive pneumococcal infections has been demonstrated (11).

\author{
Les rendez-vous attribuables aux infections des \\ voies respiratoires inférieures et à l'otite moyenne \\ par rapport à l'utilisation du vaccin conjugué \\ contre le pneumocoque en Saskatchewan
}

HISTORIQUE : En Saskatchewan, le vaccin conjugué contre le pneumocoque (VCP) est offert aux enfants très vulnérables depuis 2002, et à tous les nourrissons depuis 2005.

OBJECTIF : Décrire les tendances en matière de fréquence de rendezvous chez le médecin pour des infections des voies respiratoires inférieures (IVRI) ou une otite moyenne $(\mathrm{OM})$ par rapport à l'utilisation du VCP entre 1990 et 2008.

MÉTHODOLOGIE : Santé Saskatchewan a fourni les statistiques relatives au nombre d'enfants couverts par le régime d'assurance-maladie, à l'administration du VCP et aux rendez-vous médicaux dont le code médical s'associait à une IVRI ou à une OM. Les chercheurs ont analysé les taux mensuels au moyen de modèles dynamiques à espace d'état.

RÉSULTATS : Dans toutes les séries, les chercheurs ont constaté un cycle saisonnier marqué et certaines valeurs hivernales de pointe plus élevées que prévu, qui s'associaient peut-être à des épidémies de virus respiratoires particuliers. Ils ont observé trois diminutions abruptes des taux de départ pour ce qui est des IVRI. La dernière, en février 2007, pourrait être liée à l'augmentation de la proportion d'enfants ayant reçu le VCP. Ils n'ont remarqué aucune corrélation statistique entre l'utilisation du VCP et la fréquence des rendez-vous liés à l'OM.

CONCLUSION : De nombreux facteurs environnementaux, biologiques et administratifs peuvent influer sur l'utilisation des services de santé, et l'effet marginal d'un certain vaccin sur des issues non spécifiques peut être masqué dans des analyses de séries chronologiques.

The objective of the present study was to describe trends in the frequency of medical visits for lower respiratory tract infection (LRI) and OM in children $<5$ years of age in Saskatchewan in relation to PCV-7 use during the period 1990 to 2008. An initial hypothesis was that the monthly frequency of visits would be inversely correlated with the increasing prevalence of vaccinated children following PCV-7 introduction. An alternative hypothesis was that a downward break in baseline frequency rates would be apparent when a high proportion of children had been vaccinated, a threshold causing an interruption in the transmission of vaccine-type pathogens (herd effect).

Population denominators

\section{METHODS}

Population denominators were defined as the number of children covered by Saskatchewan Health (the provincial health insurance system) for at least one day in a given month and who had not self-declared as Registered Indians (the terminology used in the database). The 15th of the month was used to calculate the age of each child.

\section{PCV-7 uptake rates}

In Saskatchewan, most publicly funded vaccines for children are administered by public health nurses. Information pertaining to vaccine

${ }^{1}$ Quebec National Public Health Institute, Quebec City, Quebec; ${ }^{2}$ Department of Pediatrics, University of Saskatchewan, Saskatoon; ${ }^{3}$ Population Health Branch, Ministry of Health, Regina, Saskatchewan; ${ }^{4}$ GlaxoSmithKline, Mississauga (currently Eastlake Research Group, Oakville), Ontario; ${ }^{5}$ Department of Social and Preventive Medicine, Laval University; ${ }^{6}$ Quebec University Hospital Research Centre, Quebec City, Quebec Correspondence: Dr Philippe De Wals, Département de Médecine sociale et préventive, Université Laval, CRIUCPQ, 2725 chemin Sainte-Foy, Québec, Quebec G1V 4G5. Telephone 418-656-8711 ext 3248, fax 418-656-4614, e-mail philippe.dewals@criucpq.ulaval.ca 


\begin{tabular}{|c|c|c|c|}
\hline Diagnostic category & $\begin{array}{l}\text { ICD-9 } \\
\text { code }\end{array}$ & $\begin{array}{l}\text { Visits, } \\
\mathrm{n}\end{array}$ & $\begin{array}{c}\text { Rate per } \\
100,000 \\
\text { person-months }\end{array}$ \\
\hline \multicolumn{4}{|l|}{ Lower respiratory infections } \\
\hline Acute bronchitis and bronchiolitis & 466 & 118,035 & 966 \\
\hline Viral pneumonia & 480 & 448 & 4 \\
\hline Pneumococcal pneumonia & 481 & 1329 & 11 \\
\hline Other bacterial pneumonia & 482 & 192 & 2 \\
\hline Pneumonia due to other specified organism & 483 & 144 & 1 \\
\hline $\begin{array}{l}\text { Pneumonia in infectious diseases } \\
\text { classified elsewhere }\end{array}$ & 484 & 0 & 0 \\
\hline Bronchopneumonia, organism unspecified & 485 & 12,013 & 98 \\
\hline Pneumonia, organism unspecified & 486 & 37,703 & 308 \\
\hline Bronchitis not specified as acute or chronic & 490 & 114,891 & 940 \\
\hline Empyema & 510 & 58 & 0 \\
\hline Pleurisy & 511 & 147 & 1 \\
\hline All categories & & 284,960 & 2331 \\
\hline Otitis media & 381-382 & 729,490 & 5968 \\
\hline
\end{tabular}

ICD-9 International Classification of Diseases, Ninth Revision

administration is directly recorded by vaccinators in the web-based Saskatchewan Immunization Management System (SIMS), which contains the client's identifier, date of birth, date of vaccine administration, and vaccine type or brand name. The data exclude children who are immunized in the First Nations communities, who have moved to Saskatchewan but have not yet been in contact with a regional health authority or been immunized, children whose immunization records were not entered into the SIMS database, and those with inactive status in the registry. Conversely, SIMS includes those who moved out of the province without providing notice to Saskatchewan Health. Aggregated data regarding the number of children who had received a first, second, third or fourth PCV-7 dose by age (in months) and by date ( $\mathrm{dd} / \mathrm{mm} / \mathrm{yy}$ ) were obtained. From this, the cumulative number of children $<5$ years of age who had received a first, second, third and fourth dose was estimated at the 15th of each month. The monthly proportion of vaccinated children was used as a candidate explanatory variable in modelling.

\section{Medical visits}

The Medical Service Plan in Saskatchewan records every service for which a physician is claiming payment. Services delivered by physicians in salaried or contractual arrangements and not reported in shadow billing are not included. Services delivered by nurse practitioners based in a physician's office have been captured since April 1, 1996. Claims include outpatient, inpatient and emergency department visits, telephone consultations, diagnostic tests and treatments. Medical visits were compiled by collapsing service claims with a common patient identifier, date and location of service, practitioner number, clinic number and diagnostic code (three-digit codes of the Ninth Revision of the WHO International Classification of Disease - ICD-9). Aggregated data regarding the number of visits and the number of children making those visits according to diagnostic category, single-year age category and calendar month were obtained. Diagnostic categories of interest are listed in Table 1. Monthly rates were computed using the number of individuals covered by Saskatchewan Health in the denominator.

\section{Statistical analyses}

Descriptive statistical analyses were performed using $\mathrm{R}$ software version 2.13.20 ( $\mathrm{R}$ Foundation for Statistical Computing, Austria). Monthly rates were computed for LRI and OM in children $<5$ years of age, and in those $<2$ years of age to take into account the higher incidence of pneumococcal infections in this younger age group (1). A sensitivity analysis was also performed using diagnostic codes related to pneumonia (ICD-9 480 to 486) because the efficacy of pneumococcal vaccines may be greater for this subcategory (3).

Time series were modelled using STAMP (Structural Time Series Analyser, Modeller and Predictor) software version 7.0 (Timberlake Consultant Limited, United Kingdom) (12-14). The first step was to define a base model including a stochastic baseline frequency rate level and a stochastic slope (to allow for random baseline variation), a stochastic seasonal factor (to allow for variation in the timing and magnitude of winter peaks), and autoregressive terms starting with lag 1 . Thereafter, alternative models were tested for their ability to improve fitness including a deterministic (fixed) baseline level, a deterministic linear slope and a deterministic seasonal factor. Interventions including structural breaks (upward or downward shifts in the baseline level) and outliers (unusual high or low values in the series) were proposed in light of the distribution of residuals, and their statistical significance was tested. Finally, the effect of an increasing PCV-7 uptake rate was explored using three different approaches: a staircase intervention in which the candidate explanatory variable is treated as an ordinal parameter (no vaccine uptake up to August 2002; low uptake from September 2002 to March 2005; high uptake since April 2005); a continuous variable representing the monthly vaccine uptake rate ( $\geq 1$ dose or $\geq 4$ doses); and a downward break in baseline rate occurring after PCV-7 introduction as a result of herd effect.

At each step in modelling, predictions were graphically plotted against observations and residuals against a normal distribution. The DurbinWatson statistic was used to detect autocorrelation in residuals and a value close to 2 was considered to be evidence of independence $(15,16)$. Goodness of fit was assessed by Akaike information criteria, with a lower value of the statistic indicating an improvement of the balance between precision and complexity of the model (17). Statistical significance was defined as $\mathrm{P}<0.05$ (bilateral test). Two other statistics were used to confirm the predictive value of each model over a 24-month period (January 2007 to December 2008): the sum of squared prediction errors (SPE) and the sum of squared prediction residues (SPR) (12). The lower the value of these two indexes, the better the predictive value of the model.

\section{RESULTS}

PCV uptake rates

Monthly PCV-7 uptake rates in children $<5$ years of age are shown in Figure 1. During the period from September 2002 to March 2005, PCV-7 was offered to high-risk children only and the proportion of vaccinated children remained low. As soon as PCV-7 was freely offered to all infants, the prevalence of vaccinated children rapidly increased and, by the end of the observation period, close to $80 \%$ of children $<5$ years of age had received at least one PCV -7 dose. As expected, the proportion of children who had received the fourth booster dose lagged behind. Divergence in trends is an indication of the existence of a small, albeit constant, proportion of children who received a fewer number of doses than recommended.

\section{LRIs}

From 1990 to 2008, 284,960 visits with a LRI code were recorded in the study population, representing $12,222,813$ person-months of observation (Table 1). The average monthly rate was 2331 per 100,000 person-months, meaning that each child received this diagnosis 1.4 times by five years of age. Bronchitis and bronchiolitis (ICD-9 codes 466 and 490) were the most frequent diagnostic categories, representing $82 \%$ of the total cases. All-cause pneumonia (ICD-9 480 to 486 ) accounted for $18 \%$ of the total cases.

The observed and predicted monthly LRI rates are shown in Figure 2. The baseline level was better explained by a stochastic rather than a deterministic variable, indicating a relative instability in the series. For clarity, however, the stochastic nature of the baseline was not represented in the predicted series. There was a marked seasonal variation, with winter peaks and low rates during summer months, which was better explained by a deterministic rather than a stochastic variable, indicating a reproducible seasonal effect. No linear slope could be detected but there were statistically significant abrupt decreases 


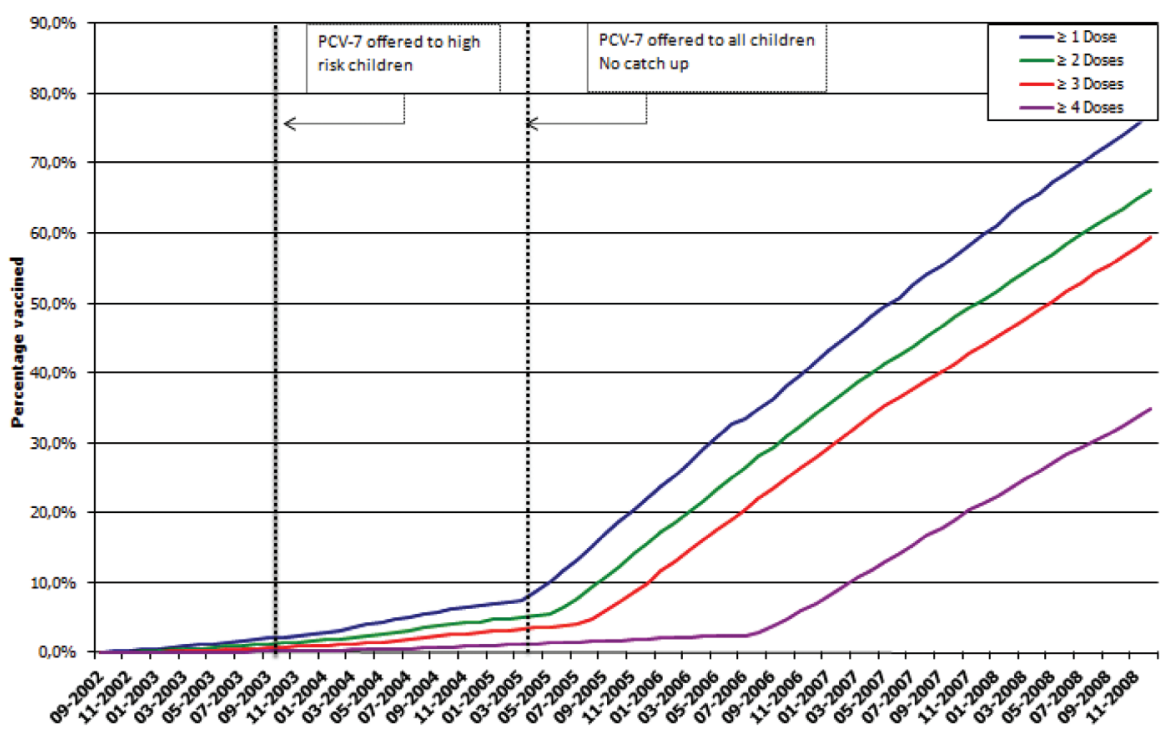

Figure 1) Proportion of children $<5$ years of age who had received $\geq 1$ to $\geq 4$ doses of the seven-valent pneumococcal conjugate vaccine (PCV-7) at the 15th of each month from September 2002 to December 2008, in Saskatchewan

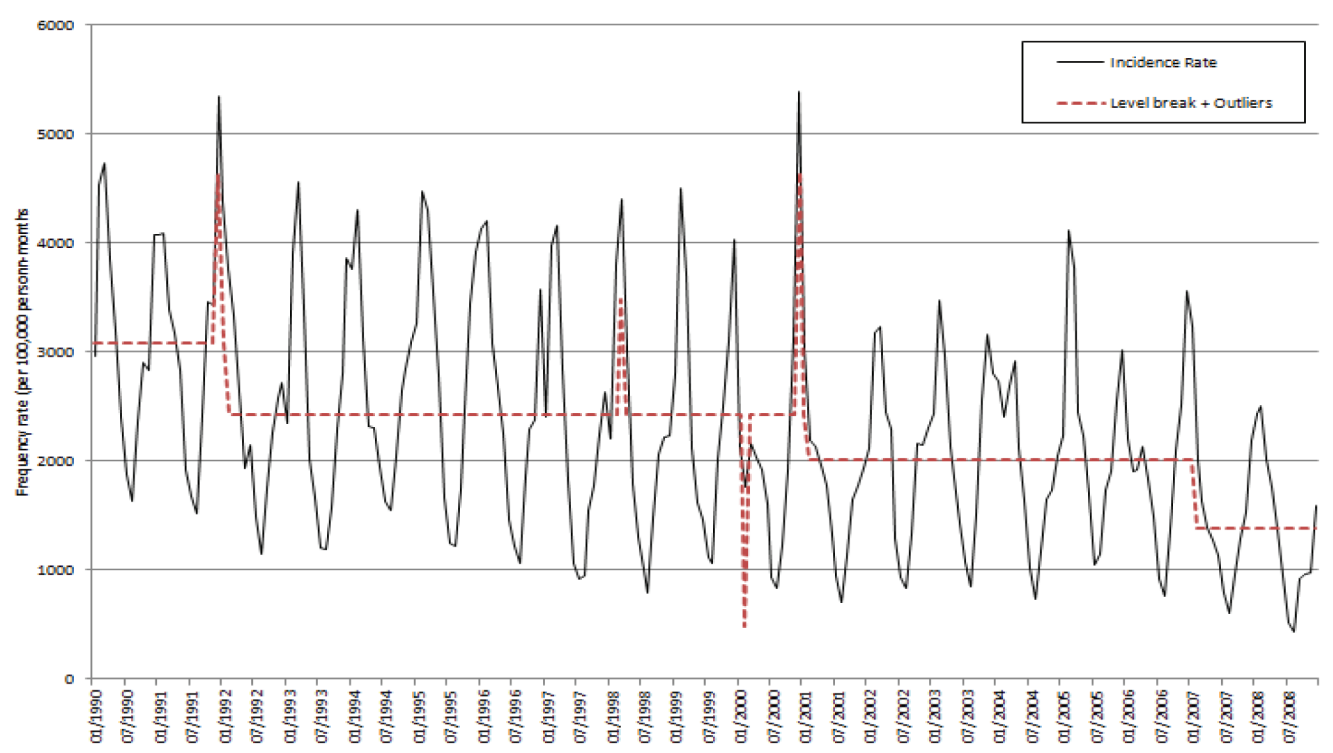

Figure 2) Observed and predicted monthly rates of visits with a diagnosis of lower respiratory infection among children $<5$ years of age in Saskatchewan, 1990 to 2008. The predicted series includes the baseline level coefficient, level breaks and outliers. The stochastic nature of the baseline frequency rate is not represented to better display level breaks

(downward breaks) in baseline, respectively, in February 1992, February 2001 and February 2007. Higher-than-expected values were identified in December 1991, March 1993, March 1998 and December 2000, whereas a lower-than-expected value was apparent in February 2000. Regardless of the definition used, the increasing vaccine uptake rate was not a statistically significant predictor in the model. Details regarding the parameters are summarized in Appendix 1.

A second analysis (Figure 3) was restricted to diagnostic categories covering all-cause pneumonia in children $<2$ years of age (ICD-9 codes 480 to 486). The same features as observed in the previous analysis were present: a stochastic baseline rate and a deterministic seasonal effect, winter outliers and a statistically significant decrease (downward break) in the baseline rate in February 2007. Details regarding the parameters are summarized in Appendix 2.

\section{$\mathrm{OM}$}

As shown in Table 1, visits for OM (5968 per 10,000 person-months) were significantly more frequent than visits for LRI (2331 per
100,000 person-months). The average number of visits per child for $\mathrm{OM}$ was 3.6 up to the fifth birthday.

The OM time series is presented in Figure 4. There was a marked seasonal variation and a decreasing trend over time, more curvilinear than linear. The best model included a stochastic baseline level and a deterministic seasonal effect. Statistically significant downward shifts in baseline occurred, respectively, in February 1992 and May 1993. Unusually high values were observed in March 1993, March 1998, February 1999, December 1999 and December 2000. A lowerthan-expected value was observed in January 2007. No statistically significant effect of PCV-7 use could be identified, regardless of the definition used. Details regarding the parameters are summarized in Appendix 3.

An additional, more specific analysis was performed on the OM rate in children six to 23 months of age (Figure 5). The characteristics of the previous analysis were present in the time series and no effect of PCV-7 use could be demonstrated. Details regarding the parameters are summarized in Appendix 4. 


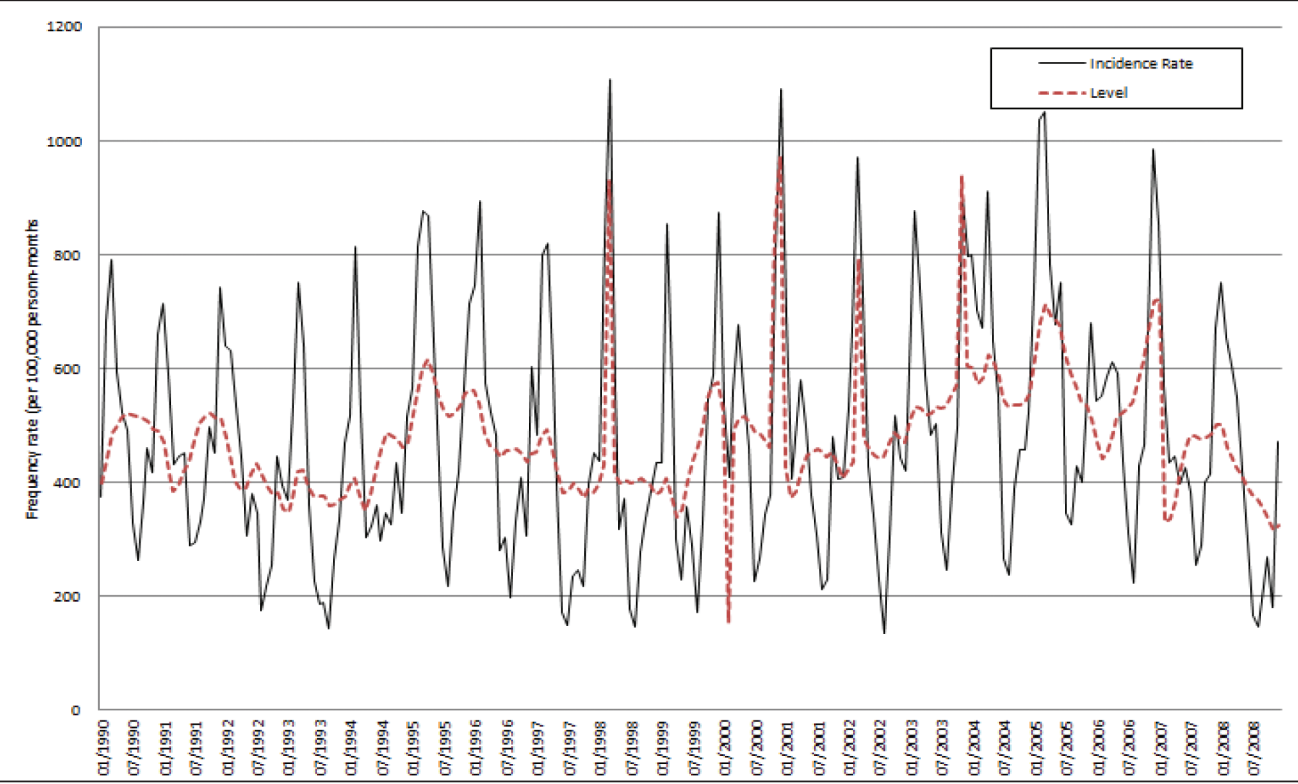

Figure 3) Observed and predicted monthly rates of visits with a diagnosis of pneumonia among children <2 years of age in Saskatchewan, 1990 to 2008

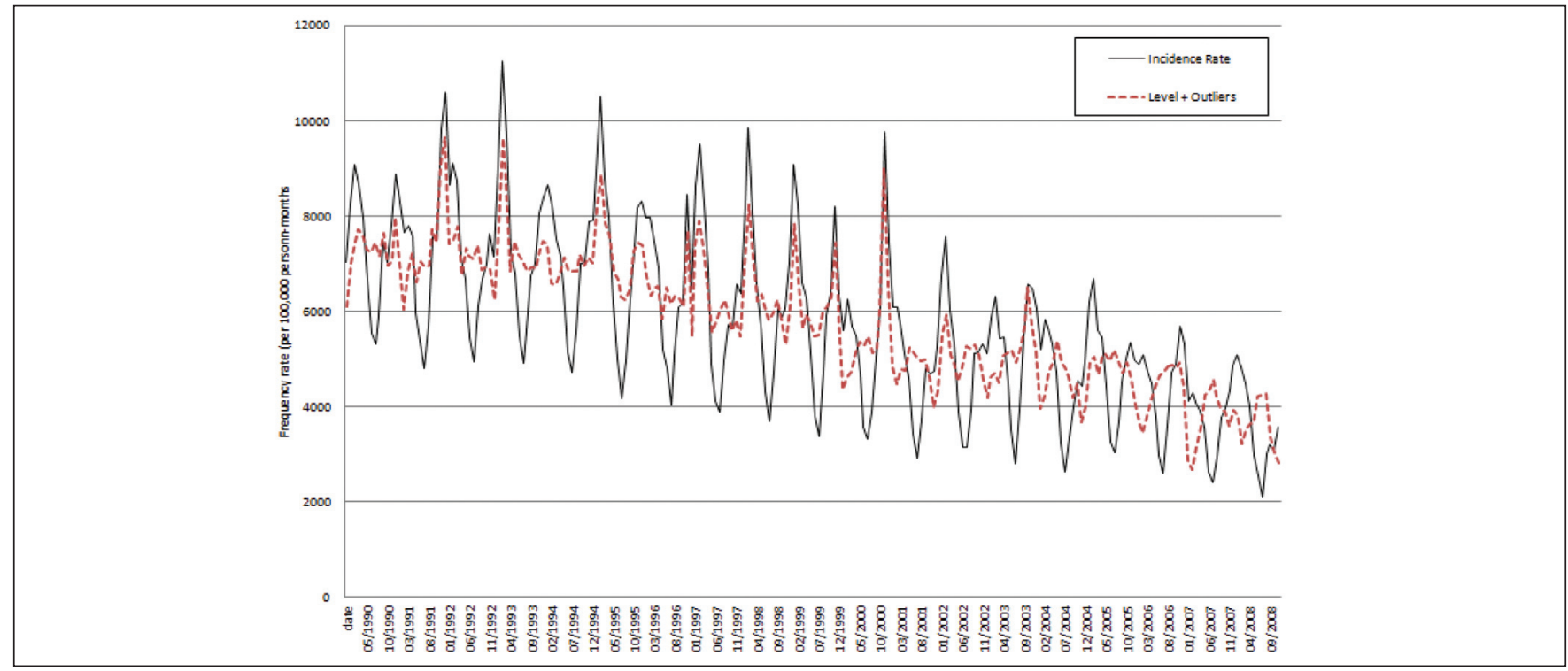

Figure 4) Observed and predicted monthly rates of visits with a diagnosis of otitis media among children <5 years of age in Saskatchewan, 1990 to 2008

\section{DISCUSSION}

In Saskatchewan, there was a decreasing trend in the frequency of medical visits for LRI and OM during the 19-year study period (1990 to 2008). The abrupt decease (downward break) in the baseline rate observed for LRI and all-cause pneumonia in February 2007 could be related to PCV-7 use. At that time, $45 \%$ of children $<5$ years of age had received $\geq 1 \mathrm{PCV}-7$ dose and $9 \%$ had received the recommended four doses. The uptake rate was certainly higher among toddlers but it is the group of children between two to five years of age in which the peak of nasopharyngeal carriage of Streptococcus pneumoniae is usually observed in developed countries (18). Three successive downward breaks in the LRI baseline rate were detected during the study period, the first and second occurring before PCV-7 had been licensed in Canada. Thus, we cannot exclude the role of other, unmeasured factors to explain these variations. Also, we were unable to demonstrate any effect of PCV-7 use on the frequency of visits for OM.

Many studies have been performed in North America and Europe to assess the impact of PCV-7 on health services uses, including hospitalization for pneumonia and outpatient visits for acute OM (19-21). The majority of these studies covered short periods of time and/or ignored pre-existing trends in baseline rates. In a recent review (21), the authors advocated the use of time-series modelling to better estimate the impact of pneumococcal conjugate vaccines at the population level.

Dynamic state space models with observed and unobserved components have been specifically designed for identifying the inner structure of time series and forecasting (12-14). Using this analytical method, a statistically significant inverse association was observed between the frequency of physician claims for $\mathrm{OM}$ and the increasing uptake of PCV-7 in children $<5$ years of age in Quebec (9). A similar observation was made for hospitalizations attributable to pneumonia, using a different statistical approach (8). In Quebec, the introduction of PCV-7 in the routine immunization schedule was associated with a rapid and extensive catch-up for children up to five years of age (22). It may be that PCV-7 introduction at a slow pace, as seen in Saskatchewan, produces a mild beneficial effect that is obscured by the dynamic of serotype replacement. This phenomenon was apparent with invasive pneumococcal disease (5-7). There is significantly wider diversity in the bacteria causing OM and LRI than in those causing 


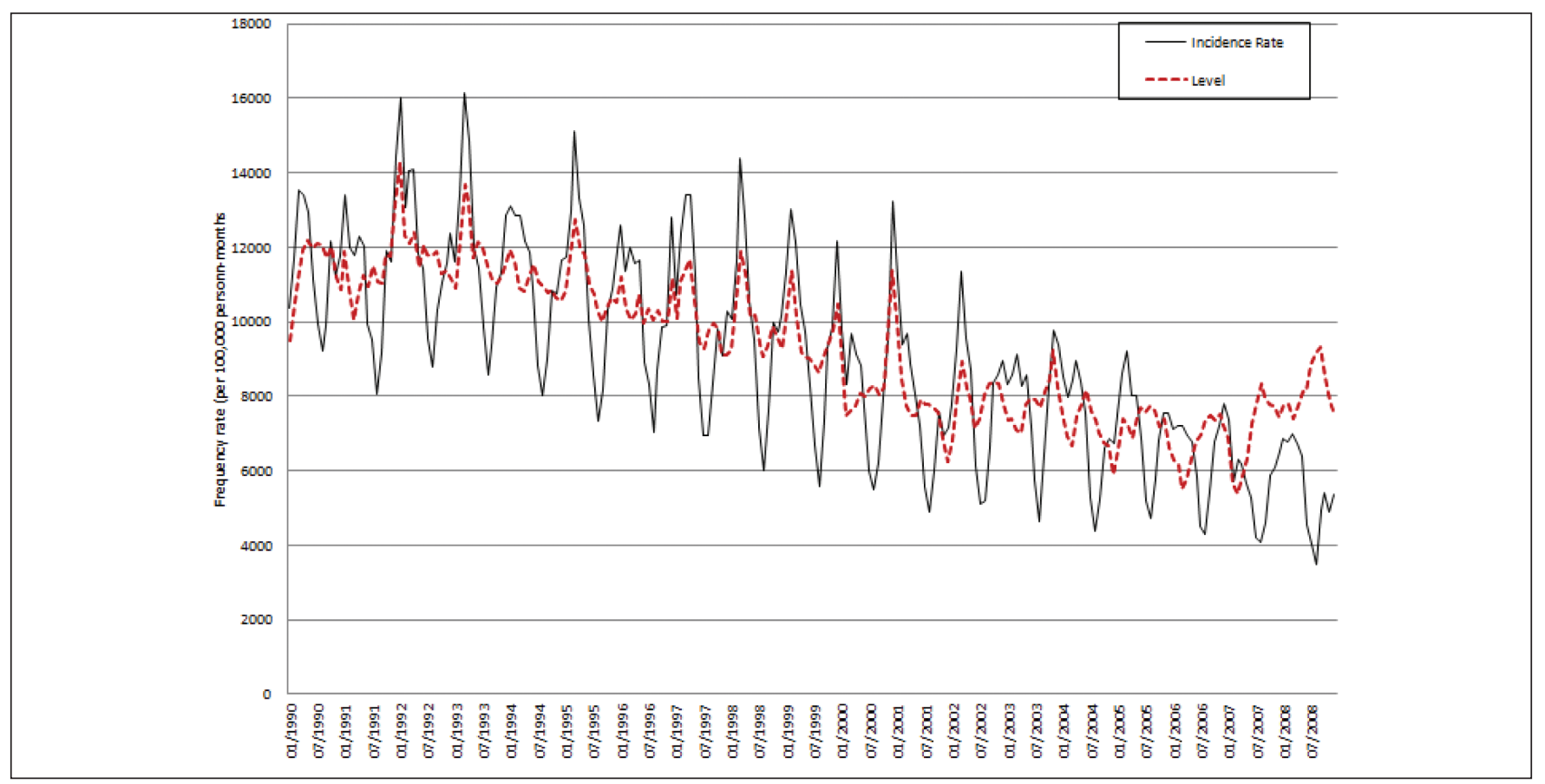

Figure 5) Observed and predicted monthly rates of visits with a diagnosis of otitis media in children six to 23 months of age in Saskatchewan, 1990 to 2008

invasive diseases, and candidates for replacement are numerous $(23,24)$. In all series, there was a marked seasonal cycle and some higher-than-expected winter peak values possibly associated with epidemics of specific respiratory viruses. Unfortunately, precise information regarding the circulation of respiratory viruses in the population was not available for the entire study period.

Administrative databases are far from perfect tools to study the health effects of vaccines at the population level, but there are no other affordable options (25). The data from Saskatchewan excluded children with self-declared Registered Indian status, but First Nations children who were not self-declared remained in the data. Immunizations delivered in First Nations clinics were not recorded in the data, but all physician services were included. This may have introduced a small, albeit constant, bias in the series and could also affect the external validity of results and extrapolation of conclusions to First Nations children.

Diagnostic information is derived from physician billing claims, which have less specific diagnostic coding than hospital claims. Each physician claim contains a single three-digit ICD diagnostic code and no validation of the quality of diagnostic codes could be performed. We have to assume that the practice of billing is relatively stable over time for most physicians and that turnover in the profession is of low magnitude and cannot produce abrupt changes in the series.

To conclude, many factors may influence health services use and an effect of low magnitude of PCV pertaining to nonspecific outcomes could be obscured in time-series analyses. In the future, it would be interesting to extend our analysis to the period of PCV-13 use.

ACKNOWLEDGEMENTS: The study was supported by an investigator initiated unrestricted research grant from GlaxoSmithKline, Mississauga, Ontario. The sponsor had no input into the study design, analysis or interpretation of results. The first author received an educational grant from the Institut national de santé publique du Québec. Statistical advice was provided by Michel Carbon, Department of Applied Mathematics and Social Sciences, University Rennes-2, Haute-Bretagne, France.

DISCLAIMER: This study was based, in part, on deidentified data provided by the Saskatchewan Ministry of Health. The interpretation and conclusions contained herein do not necessarily represent those of the Government of Saskatchewan or the Saskatchewan Ministry of Health.

\section{REFERENCES}

1. National Advisory Committee on Immunization (NACI). Statement on recommended use of pneumococcal conjugate vaccine. CCDR 2002;28ACS-2:1-32.

2. Black S, Shinefield H, Fireman B, et al. Efficacy, safety and immunogenicity of heptavalent pneumococcal conjugate vaccine in children. Pediatr Infect Dis J 2000;19:187-95.

3. Black SB, Shinefield HR, Ling S, et al. Effectiveness of heptavalent pneumococcal conjugate vaccine in children younger than five years of age for prevention of pneumonia. Pediatr Infect Dis J 2002;21:810-15.

4. Eskola J, Kilpi T, Palmu A, et al. Efficacy of a pneumococcal conjugate vaccine against acute otitis media. N Engl J Med 2001;344:403-9.

5. Weinberger DM, Malley R, Lipsitch M. Serotype replacement in disease after pneumococcal vaccination. Lancet 2011;378:1962-73.

6. Pilishvili T, Lexau C, Farley MM, et al. Sustained reductions in invasive pneumococcal disease in the era of conjugate vaccine. J Infect Dis 2010;201:32-41.

7. Miller E, Andrews NJ, Waight PA, Slack MPE, George RC. Herd immunity and serotype replacement 4 years after seven-valent pneumococcal conjugate vaccination in England and Wales: An observational cohort study. Lancet Infect Dis 2011;11:760-8.

8. De Wals P, Robin É, Fortin É, Thibeault R, Ouakki M, Douville-Fradet M. Pneumonia after implementation of the pneumococcal conjugate vaccine program in the province of Quebec, Canada. Pediatr Infect Dis J 2008;27:963-8.

9. De Wals P, Carbon M, Sévin E, Deceuninck G, Ouakki M. Reduced physician claims for otis media after implementation of pneumococcal conjugate vaccine in the province of Quebec, Canada. Pediatr Infect Dis J 2009;28:e271-4.

10. Deceuninck G, De Wals P, Boulianne N, De Serres G. Effectiveness of pneumococcal conjugate vaccine using a $2+1$ infant schedule in Quebec, Canada. Pediatr Infect Dis J 2010;29:546-9.

11. Leal J, Vanderkooi OG, Church DL, Macdonald J, Tyrrell GJ, Kellner JD. Eradication of invasive pneumococcal disease due to the seven-valent pneumococcal conjugate vaccine serotypes in Calgary, Alberta. Pediatr Infect Dis J; 2012 31:e169-75

12. Harvey A, Koopman J. Structural time series models in medicine. Stat Methods Med Res 1996;5:23-49.

13. Harvey A. Forecasting with unobserved components time series models. In: Elliott G, Granger CWJ, Timmermann A, eds. Handbooks of Economics Forecasting, Vol 1. Amsterdam: North Holland, 2006:327-408.

14. Koopman SJ, Harvey AC, Doornik JA, Shephard N. STAMP: Structural Time series Analyser, Modeller and Predictor. London: Timberlake Consultants Press, 2006.

15. Durbin J, Watson GS. Testing for serial correlation in least squares regression, I. Biometrika 1950;37:409-28.

16. Durbin J, Watson GS. Testing for serial correlation in least squares regression, II. Biometrika 1951;38:159-79. 
17. Akaike H. A new look at the statistical model identification. IEEE Transactions on Automatic Control 1974;19:716-23.

18. O’Brien KL, Dagan R, Mäkelä PH. Nasopharyngeal carriage. In: Siber GR, Klugman KP, Mäkelä PH, eds. Pneumococcal Vaccines. The Impact of Conjugate Vaccine. Washington (DC): ASM Press, 2008:279-300.

19. Grijalva CG, Griffin MR. Population-based impact of routine infant immunization with pneumococcal conjugate vaccine in the USA. Expert Rev Vaccines 2008;7:83-95.

20. Rose M, Zielen S. Impact of infant immunization programs with pneumococcal conjugate vaccine in Europe. Expert Rev Vaccines 2009;8:1351-64.

21. Taylor S, Marchisio P, Vergison A, Harriague J, Hausdorff WP, Haggard M. Impact of pneumococcal conjugate vaccination on otitis media: A systematic review. Clin Infect Dis 2012;54:1765-73.

\section{APPENDIX 1}

Model predicting monthly rate of visits for lower respiratory infection in children $<5$ years of age in Saskatchewan, 1990 to 2008

\begin{tabular}{llcr}
\hline Characteristic & Parameter & Coefficient value & P \\
\hline Model fit & & & \\
& AIC & 12.17 & \\
& R $^{2}$ & 0.86 & \\
& DW & 1.82 & \\
Significant predictors & & \\
& Baseline level & Stochastic & \\
& Seasonality & Deterministic & \\
& Level break, February 1992 & -1423 & 0.0006 \\
& Level break, February 2001 & -1646.8 & $<0.0001$ \\
& Level break, February 2007 & -2079 & $<0.0001$ \\
& Outlier, December 1991 & 1059 & 0.0011 \\
& Outlier, March 1993 & 976 & 0.0023 \\
& Outlier, February 2000 & -1164 & 0.0003 \\
& Outlier, December 2000 & 2016 & $<0.0001$
\end{tabular}

Predictive performance over a 24-month horizon: January 2007 to December 2008

$$
\begin{array}{lc}
\text { SPE } & 2.48 \times 10^{6} \\
\text { SPR } & 14.63
\end{array}
$$

AIC Akaike's information criteria; DW Durbin-Watson statistics; SPE Squared prediction errors; SPR Squared prediction residuals

\section{APPENDIX 2}

Model predicting monthly rate of visits for all-cause pneumonia in children $<2$ years of age in Saskatchewan, 1990 to 2008

\begin{tabular}{llcl}
\hline Characteristic & Parameter & Coefficient value & $\mathbf{P}$ \\
\hline Model fit & & \\
& AIC & 9.58 \\
& $\mathrm{R}^{2}$ & 0.74 \\
& DW & 1.67
\end{tabular}

Significant predictors

$\begin{array}{lcr}\text { Baseline level } & \text { Stochastic } & \\ \text { Seasonality } & \text { Deterministic } & \\ \text { Level break, February 2007 } & -392 & <0.0001 \\ \text { Outlier, March 1998 } & 506 & <0.0001 \\ \text { Outlier, February 2000 } & -357 & 0.0006 \\ \text { Outlier, November 2000 } & 398 & 0.0002 \\ \text { Outlier, December 2000 } & 532 & <0.0001 \\ \text { Outlier, March 2002 } & 335 & 0.0013 \\ \text { Outlier, November 2003 } & 350 & 0.0008\end{array}$

Predictive performance over a 24-month horizon: January 2007 to December 2008

$$
\begin{array}{lc}
\text { SPE } & 1.79 \times 10^{5} \\
\text { SPR } & 13.33
\end{array}
$$

$\overline{\text { AIC Akaike's information criteria; DW Durbin-Watson statistics; SPE Squared }}$ prediction errors; SPR Squared prediction residuals
22. De Wals P, Boulianne N, Sévin E, Ouakki M, Deceuninck G, Guay M. Uptake of pneumococcal conjugate vaccine: Methodological issues in measurement and impact of publicly funded programs. Can J Public Health 2009;100:413-6.

23. Hausdorff WP, Dagan R. Serotypes and pathogens in paediatric pneumonia. Vaccine 2008;26(Suppl 2):B19-23.

24. Hausdorff WP, Feikin DR, Klugman KP. Epidemiological differences among pneumococcal serotypes. Lancet Infect Dis 2005;5:83-93

25. Rawson NSB, Downey W, Maxwell CJ, West R. 25 years of pharmacoepidemiologic innovation: The Saskatchewan health administrative databases. J Popul Ther Clin Pharmacol 2011;18:e245-e249.

\section{APPENDIX 3}

Model predicting monthly rate of visits for otitis media in children <5 years in Saskatchewan, 1990 to 2008

\begin{tabular}{llcc}
\hline Characteristic & Parameter & Coefficient value & $\mathbf{P}$ \\
\hline Model fit & & & \\
& AIC & 12.65 \\
& R $^{2}$ & 0.93 \\
& DW & 1.97
\end{tabular}

Significant predictors

$\begin{array}{lcr}\text { Baseline level } & \begin{array}{c}\text { Stochastic } \\ \text { Seasonality }\end{array} & \\ \text { Leterministic } & \\ \text { Level break, February 1992 } & -2277 & 0.0011 \\ \text { Outlier, March 1993 } & -1859 & 0.0005 \\ \text { Outlier, January 1997 } & 1367 & 0.0003 \\ \text { Outlier, March 1998 } & -2054 & <0.0001 \\ \text { Outlier, February 1999 } & 1105 & 0.0021 \\ \text { Outlier, December 1999 } & 1493 & 0.0003 \\ \text { Outlier, December 2000 } & 1596 & <0.0001 \\ \end{array}$

Predictive performance over a 24-month horizon: January 2007 to December 2008

$\begin{array}{lc}\text { SPE } & 6.6 \times 10^{6} \\ \text { SPR } & 23.57\end{array}$

AIC Akaike's information criteria; DW Durbin-Watson statistics; SPE Squared prediction errors; SPR Squared prediction residues

\section{APPENDIX 4}

Model predicting monthly rate of visits for otitis media in children six to 23 months of age in Saskatchewan, 1990 to 2008

\begin{tabular}{llcc}
\hline Characteristic & Parameter & Coefficient value & $\mathbf{P}$ \\
\hline Model fit & & & \\
& AIC & 13.34 \\
& R $^{2}$ & 0.93 \\
& DW & 2.04
\end{tabular}

Significant predictors

\begin{tabular}{lcr} 
Baseline level & \multicolumn{2}{c}{$\begin{array}{l}\text { Stochastic } \\
\text { Seterministic }\end{array}$} \\
Outlier, January 1991 & 1677 & 0.0021 \\
Outlier, January 1992 & 2527 & $<0.0001$ \\
Outlier, March 1998 & 1588 & 0.0035 \\
Outlier, February 1999 & 1002 & 0.0001 \\
Outlier, December 1999 & 2057 & 0.0002 \\
Outlier, December 2000 & 2664 & $<0.0001$
\end{tabular}

Predictive performance over a 24-month horizon: January 2007 to December 2008

$\begin{array}{lc}\text { SPE } & 1.37 \times 10^{7} \\ \text { SPR } & 15.11\end{array}$

AIC Akaike's information criteria; DW Durbin-Watson statistics; SPE Squared prediction errors; SPR Squared prediction residues 


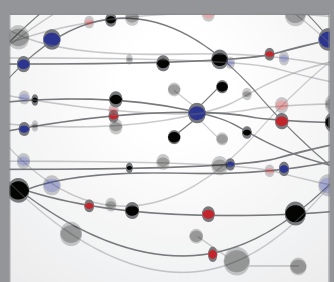

The Scientific World Journal
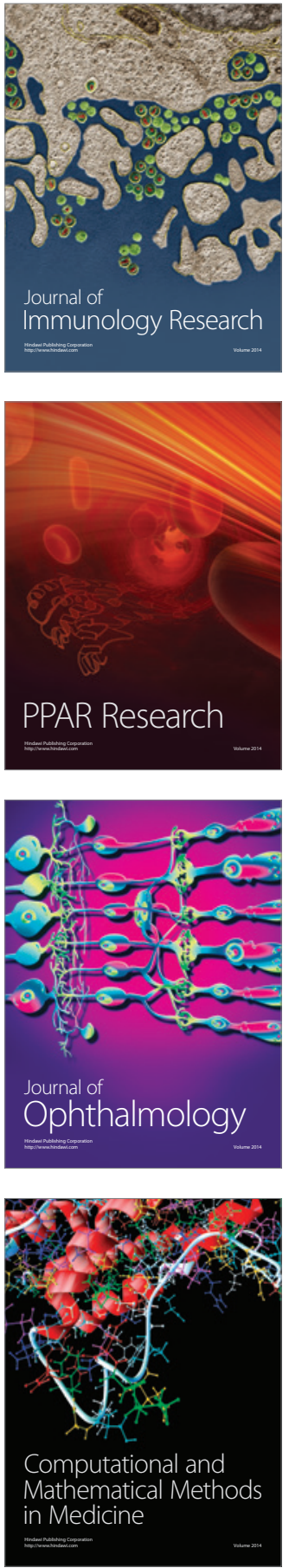

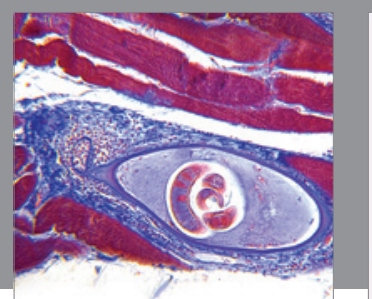

Gastroenterology Research and Practice

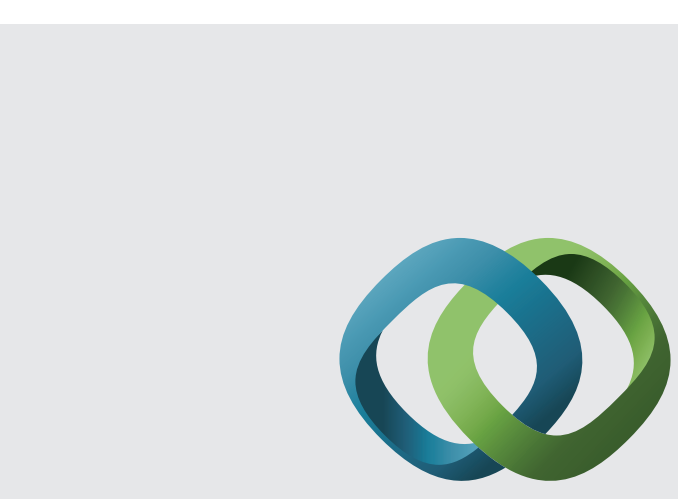

\section{Hindawi}

Submit your manuscripts at

http://www.hindawi.com
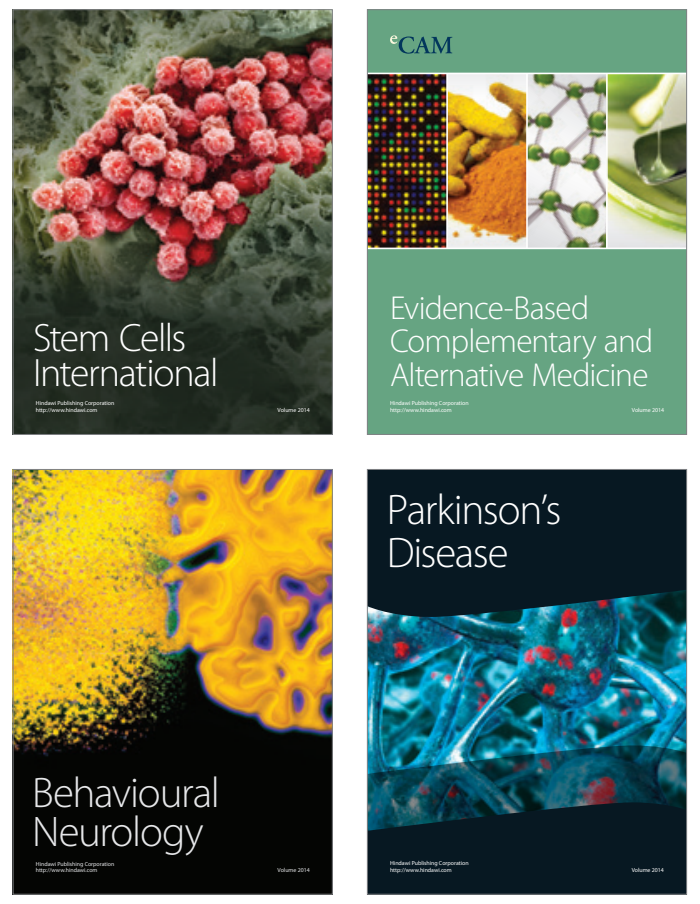
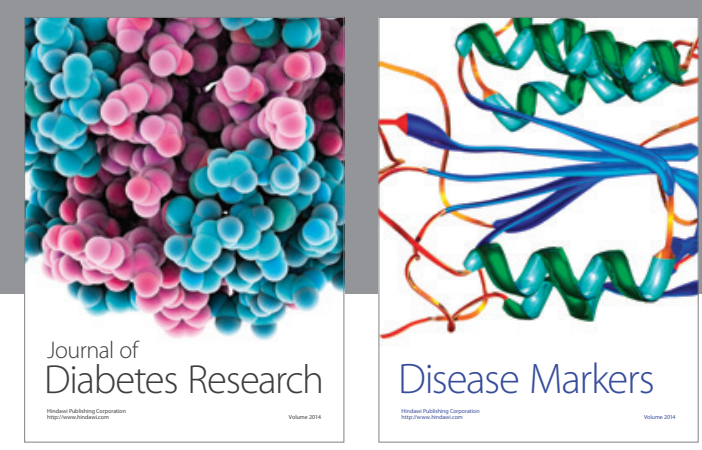

Disease Markers
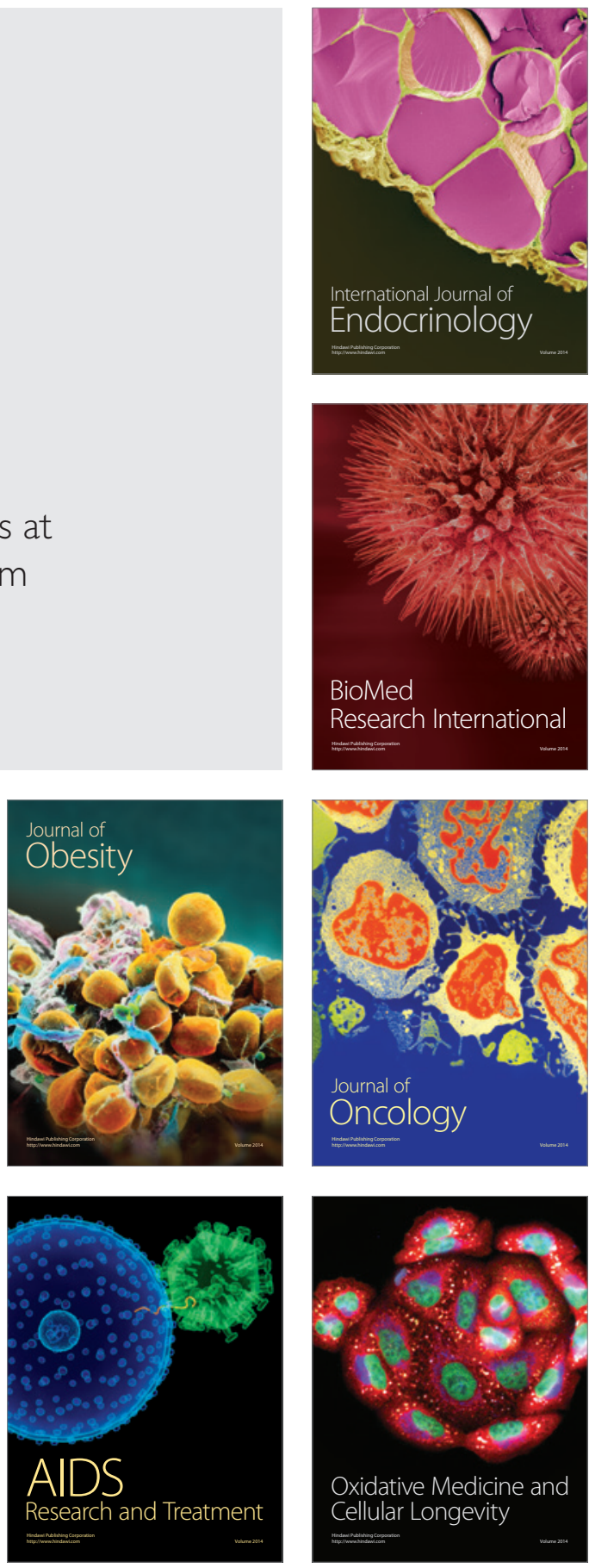